\title{
Severe Plasmodium falciparum and Plasmodium vivax malaria among adults at Kassala Hospital, eastern Sudan
}

\author{
Tajeldin M Abdallah', Mohamed T Abdeen², Ikhlas S Ahmed ${ }^{1}$, Hamdan Z Hamdan³, Mamoun Magzoub \\ and Ishag Adam²
}

\begin{abstract}
Background: There have been few published reports on severe Plasmodium falciparum and Plasmodium vivax malaria among adults in Africa.

Methods: Clinical pattern/manifestations of severe P. falciparum and P. vivax (according to World Health Organization 2000 criteria) were described in adult patients admitted to Kassala Hospital, eastern Sudan.

Results: A total of 139 adult patients (80 males, 57.6\%) with a mean (SD) age of 37.2 (1.5) years presented with severe $P$. falciparum $(113,81.3 \%)$ or $P$. vivax $(26,18.7 \%)$ malaria. Manifestations among the 139 patients included hypotension $(38,27.3 \%)$, cerebral malaria $(23,16.5 \%)$, repeated convulsions $(18,13.0 \%)$, hypoglycaemia $(15,10.8 \%)$, hyperparasitaemia $(14,10.1 \%)$, jaundice $(14,10.1 \%)$, severe anaemia $(10,7.2 \%)$, bleeding (six, $4.3 \%)$, renal impairment (one, $0.7 \%)$ and more than one criteria $(27,19.4 \%)$. While the geometric mean of the parasite count was significantly higher in patients with severe $P$. vivax than with severe $P$. falciparum malaria $(5,934.2$ vs $13,906.6$ asexual stage parasitaemia per $\mu \mathrm{L}, p=0.013$ ), the different disease manifestations were not significantly different between patients with $P$. falciparum or P. vivax malaria. Three patients (2.2\%) died due to severe P. falciparum malaria. One had cerebral malaria, the second had renal impairment, jaundice and hypoglycaemia, and the third had repeated convulsions and hypotension.
\end{abstract}

Conclusions: Severe malaria due to P. falciparum and P. vivax malaria is an existing entity among adults in eastern Sudan. Patients with severe $P$. falciparum and $P$. vivax develop similar disease manifestations.

Keywords: Plasmodium falciparum, Plasmodium vivax, Severe malaria, Sudan

\section{Background}

Malaria is a big health problem and is endemic in an area where around two billion people live. Plasmodium falciparum causes approximately 600,000 deaths each year and the vast majority of the burden of malaria mortality is in sub-Saharan African countries [1]. The high mortality rate from $P$. falciparum is due to its ability to induce severe malaria, and in some cases, multiple organ dysfunction [2]. The presenting symptoms and mortality patterns of severe malaria vary widely according to the geographical setting and therefore transmission intensity. In areas with high, stable

\footnotetext{
* Correspondence: ishagadam@hotmail.com

${ }^{2}$ Faculty of Medicine, University of Khartoum, PO Box 102, Khartoum, Sudan Full list of author information is available at the end of the article
}

transmission in sub-Saharan Africa, severe anaemia in infants, which has a relatively good prognosis, is the main presentation, and severe malaria does not occur in adults with acquired immunity [2]. In areas with moderate transmission, cerebral malaria in young children is the most common presentation. In areas with low transmission, such as Southeast Asia, severe malaria occurs in all age groups including adults. Cerebral malaria, renal failure, severe jaundice, and pulmonary oedema are the main manifestations in the young adult population [2]. Yet the determinants of severe malaria and its pathophysiology are not completely understood. Therefore, epidemiological studies of severe malaria and its related deaths may provide additional understanding of its disease course, and, eventually, lead to improved case management. 
While many data have been published on severe malaria among children in Africa, there are few published studies regarding severe malaria among adult African patients [3-5]. Furthermore, these studies had a greater emphasis on P. falciparum malaria and there have been no published data on severe Plasmodium vivax infection among African adults. Until recently, $P$. vivax was considered a benign parasite compared with $P$. falciparum. The current study was conducted at Kassala Hospital in eastern Sudan to investigate the manifestations and epidemiology of severe $P$. falciparum and $P$. vivax malaria among adult patients, so as to add to the previous studies on severe malaria in Sudan [6-8]. Such data are of paramount importance for care-givers, health planners and researchers. The geographical area is characterized by unstable malaria transmission, and P. falciparum (95\%) was the main species in the area. In contrast, $P$. vivax was considered rare and constitutes only $3 \%$ of the Plasmodium species in the area [9]. There is recent evidence that the rate of $P$. vivax malaria is increasing in this setting [10].

\section{Methods}

A descriptive hospital-based study was conducted at Kassala Hospital, eastern Sudan, during two transmission seasons (between August and December, 2011 and 2012) to investigate the presentation/manifestation of severe malaria caused by P. falciparum or P. vivax (Figure 1).

All patients, or their relatives in the case of comatose patients, provided informed consent, and their sociodemographic and clinical data (temperature, weight and fever history) were collected using standard questionnaires. Patients with one or more manifestations of severe $P$. falciparum or $P$. vivax malaria according to World Health Organization (WHO) criteria were enrolled [2]. Pregnant women were not included. These criteria included cerebral malaria (unarousable coma and assessed by Glasgow coma scale), convulsions (more than two per 24 hours), hypotension (systolic blood pressure $<70$ $\mathrm{mmHg}$ with cold extremities), severe anaemia (haemoglobin $<7 \mathrm{gm} / \mathrm{dl}$ ), jaundice (detected clinically or bilirubin levels $>3 \mathrm{mg} / \mathrm{dl}$ ), hypoglycaemia (blood glucose $<40 \mathrm{mg} / \mathrm{dl}$ ) and hyperparasitaemia (parasite count $>100,000$ asexual stage parasitaemia/ $\mu \mathrm{l}$ ) as described by WHO guidelines, and the rest were considered as uncomplicated cases [2].

Thick and thin blood films were prepared from capillary blood, stained with Giemsa, and 100 oil immersion fields were examined. The parasite density was evaluated by counting the number of asexual parasites for every 200 leukocytes, assuming a leukocyte count of 8,000 leukocytes $/ \mu$ l. All slides were double checked in a blinded manner and only considered negative if no parasites were detected in 100 oil immersion fields. If gametocytes were seen, then the count was extended to 500 oil immersion fields. Haemoglobin concentrations were estimated using a HemoCue haemoglobinometer (HemoCue AB, Angelhom, Sweden). Blood glucose was measured at baseline before quinine infusion and two hours after quinine infusion if there was clinical suspicion of hypoglycaemia using the bedside device Accu-Chek ${ }^{\mathrm{TM}}$ Multiclix (Roche Diagnostics, Mannheim Germany). The Accu-Chek ${ }^{\mathrm{TM}}$ machine was calibrated weekly and a new box of test strips was opened each time.

Resuscitation and supportive management were given according to WHO guidelines [11] including correction of hypoglycaemia with $10 \%$ glucose, termination of convulsions with intravenous diazepam if they persisted for more than three minutes. Paracetamol was given every six hours until defervescence. Those with severe anaemia (haemoglobin $<7 \mathrm{~g} / \mathrm{dl}$ ) and respiratory distress were transfused with blood screened for hepatitis and HIV. Vital signs were measured every 15 minutes for the first hour, then every two hours until 24 hours, and thereafter every six hours until patients were discharged from the hospital. Baseline investigations were performed for every patient upon admission and repeated when clinically indicated. These included measuring levels of haemoglobin, serum urea, serum creatinine, serum bilirubin and white blood cell counts.

Treatment during the first malaria season of 2011 consisted of quinine (quinine dihydrochloride, $20 \mathrm{mg}$ salt/ $\mathrm{kg}$ of loading dose, followed by $10 \mathrm{mg} / \mathrm{kg}$ three times a day over two to three hours, that was changed to oral quinine tablet when the patient could tolerate them). During the second season, intravenous artesunate was used with quinine in an open clinical trial. Artesunate was given as $2.4 \mathrm{mg} / \mathrm{kg}$ body weight at 0,12 , and $24 \mathrm{~h}$, and then daily. Each 60mg vial of artesunic acid (Guilin, Pharmaceutical Factory, Guangxi, People's Republic of China) was dissolved in $1 \mathrm{~mL}$ of $5 \%$ sodium bicarbonate to form sodium artesunate and then mixed with $5 \mathrm{~mL}$ of $5 \%$ dextrose. Details of the response to treatment will be described in a future report.

\section{Statistical analysis}

Statistical analysis was performed using SPSS software (SPSS Inc., Chicago, IL, USA) version 16.0) and double checked before analysis. Data were checked for normality, and the Student $t$-test and analysis of variance were used for normally distributed data to compare between two or more than two groups, respectively. Proportions were compared by $X^{2}$-test. $P$-values $<0.05$ were considered significant.

\section{Ethical statement}

The study received ethical approval from the Research Board at the Ministry of Health Kassala, Sudan. 


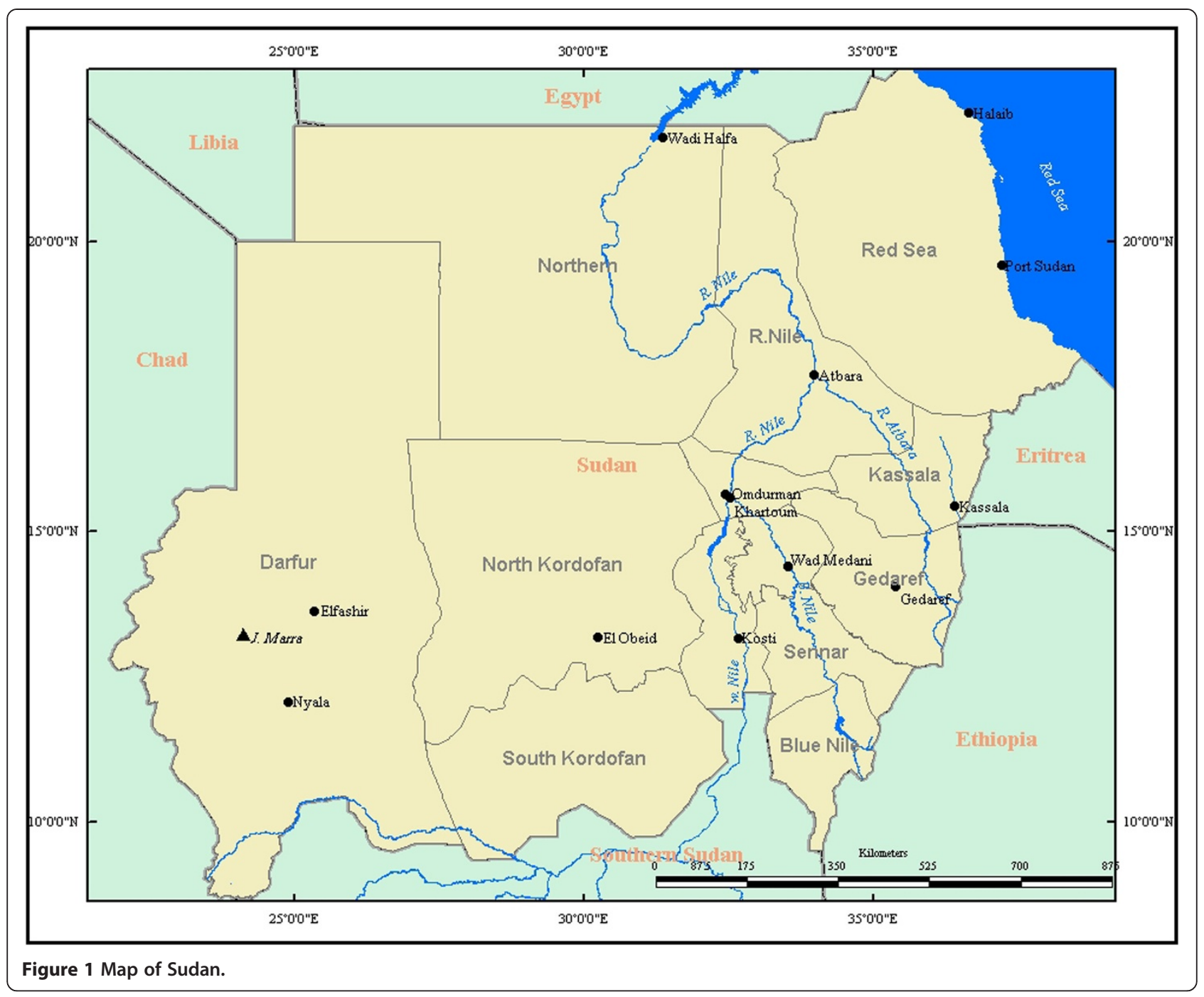

\section{Results}

Of the total 9,559 adult patients presented to the hospital during the study period, 2,124 (22.0\%) patients had malaria. Among 2,124 patients with malaria, 1,985 patients had uncomplicated malaria, 139 patients $(80$ males, 57.6\%) with a mean (SD) age of 37.2 (1.5) years presented with severe $P$. falciparum $(113,81.3 \%)$ or $P$. vivax $(26,18.7 \%)$ malaria (Figure 2$)$. The ratio of severe $P$. falciparum to severe $P$. vivax malaria was $4.3: 1.0$. There were no cases of $P$. falciparum and $P$. vivax co-infection. There was no significant difference between the manifestations/presentations in patients enrolled in the 2011 season $(55,40 \%)$ and those in the 2012 season $(84,60.0 \%)$.

Among 139 patients with either P. falciparum or $P$. vivax infection, the frequency of symptoms were as follows: hypotension $(38,27.3 \%)$, cerebral malaria (23, $16.5 \%)$, repeated convulsions $(18,13.0 \%)$, hypoglycaemia $(15,10.8 \%)$, jaundice $(14,10.1 \%)$, hyperparasitaemia (14, $10.1 \%)$, severe anaemia (10, 7.2\%), bleeding (six, $4.3 \%$ ), renal impairment (one, $0.7 \%$ ) and more than one criteria (27, 19.4\%) (Figures 2 and 3). None of the patients had respiratory distress syndrome. The different manifestations of severe malaria were not significantly different between those infected with $P$. falciparum or $P$. vivax malaria (Table 1). The geometric mean of the parasite count was significantly higher in patients with severe $P$. vivax than in patients with severe $P$. falciparum malaria $(5,934.2$ vs $13,906.6 ; P=0.013$, Table 1$)$.

Three patients presented with three manifestations of severe malaria as follows: patient 1: cerebral malaria, bleeding (epistaxis) and hypoglycaemia; patient 2: cerebral malaria with repeated convulsions and hypotension; and, patient 3: hypotension, severe anaemia and jaundice. Five patients developed severe anaemia and jaundice. There may be an overlap between the three main manifestations (hypotension, convulsion and cerebral malaria) of severe malaria. While there was no significant difference in levels of blood glucose, white blood cells and parasite counts 


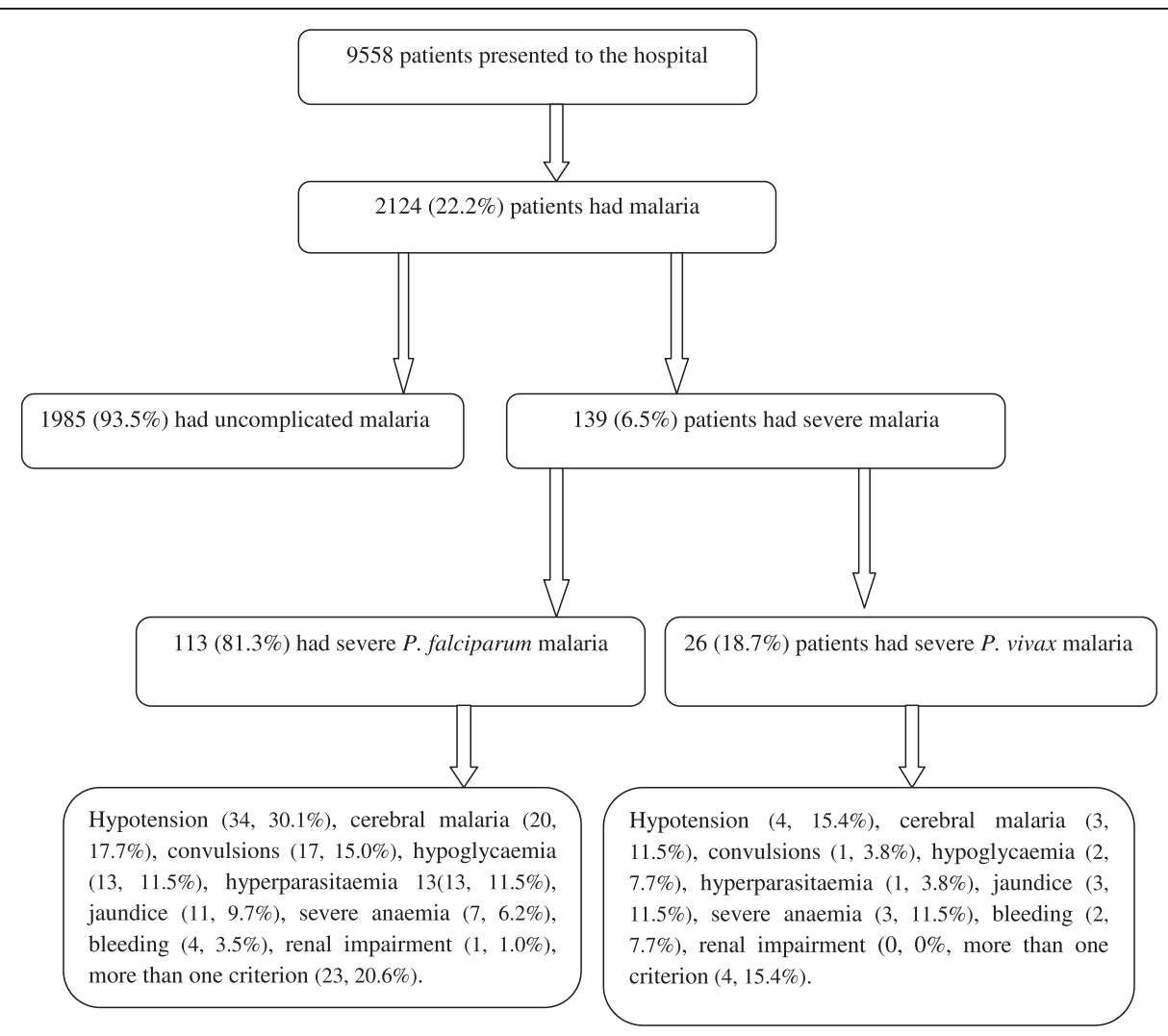

Figure 2 Clinical categorization of patients presenting with malaria-like symptoms.

between the patients presenting with hypotension, convulsion and cerebral malaria, their age (patients with cerebral malaria were older than those with convulsions, or hypotension) and haemoglobin were significantly higher in patients with cerebral malaria (Table 2).

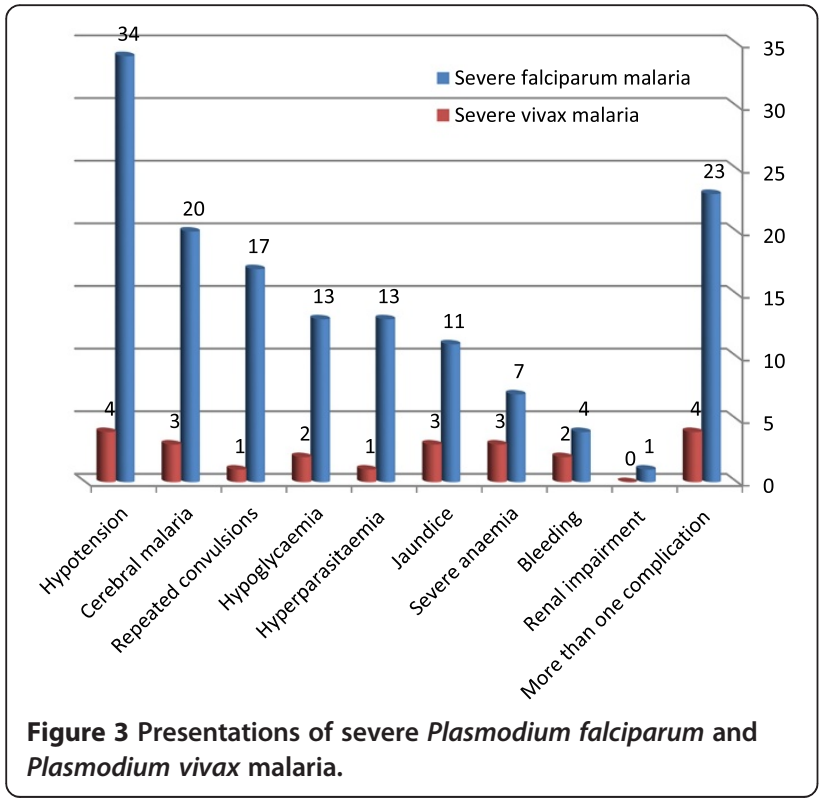

Three patients $(2.2 \%)$ died due to severe $P$. falciparum malaria. One had cerebral malaria, the second had renal impairment, jaundice and hypoglycaemia, and the third had repeated convulsions and hypotension.

\section{Discussion}

The current study demonstrated a high ratio of $P$. falciparum to $P$. vivax malaria $(4.3: 1.0)$ in patients from eastern Sudan. In addition, the predominant manifestations of severe malaria were hypotension (27.3\%), cerebral malaria (16.5\%), and convulsions (13.0\%), and their frequency was not significantly different between patients with $P$. falciparum or $P$. vivax malaria. It has been demonstrated that severe malarial anaemia was the most common complication (45.4\%) of P. falciparum malarial infection among patients in a hospital (Gedarif) in eastern Sudan [8]. The difference in dominant complications observed between the two studies may be attributable to the age difference, which ranged between two and four years in the Gedarif study compared with a range of 17-78 years, in the current study [8]. Anaemia was the most common manifestation (30\%), followed by hypoglycaemia, of severe malaria among pregnant women in the same study area [6]. Both clinical manifestations (anaemia and hypoglycaemia) were less prominent in the current study, perhaps because pregnant patients were 
Table 1 The mean (SD) [range] of the clinical and biochemical data of patients with severe Plasmodium falciparum and Plasmodium vivax malaria

\begin{tabular}{|c|c|c|c|}
\hline Variable & $\begin{array}{l}\text { P. falciparum } \\
\text { (Number }=113 \text { ) }\end{array}$ & $\begin{array}{l}\text { P. vivax } \\
(\text { Number = 26) }\end{array}$ & P-value \\
\hline \multirow[t]{2}{*}{ Age, years } & $38.0(15.5)$ & $34.2(12.6)$ & 0.260 \\
\hline & {$[18.0-78.0]$} & {$[17.0-70.0]$} & \\
\hline \multirow[t]{2}{*}{ Weight, kg } & $67.8(13.4)$ & $70.3(11.0)$ & 0.374 \\
\hline & {$[39.0-123.0]$} & {$[39.0-88.0]$} & \\
\hline \multirow[t]{2}{*}{ Duration of the illness, days } & $3.9(3.6)$ & $3.0(1.6)$ & 0.216 \\
\hline & {$[1.0-8.0]$} & {$[1.0-7.0]$} & \\
\hline \multirow[t]{2}{*}{ Axillary temperature, ${ }^{\circ} \mathrm{C}$} & $38.4(0.8)$ & $38.7(1.4)$ & 0.125 \\
\hline & {$[37.2-40.5]$} & {$[37.1-41.1]$} & \\
\hline \multirow[t]{2}{*}{ Systolic blood pressure, $\mathrm{mm} \mathrm{Hg}$} & $72.5(23.4)$ & $72.5(13.8)$ & 0.987 \\
\hline & {$[0-130.0]$} & {$[60.0-130.0]$} & \\
\hline \multirow[t]{2}{*}{ Diastolic blood pressure, mm Hg } & $47.0(17.7)$ & $50.0(10.1)$ & 0.414 \\
\hline & {$[0-100.0]$} & {$[30.0-70.0]$} & \\
\hline \multirow[t]{2}{*}{ Parasite count, rings $/ \mu \mathrm{l}$, Geometric } & $5,934.2$ & $13,906.6$ & 0.013 \\
\hline & [1600-380000] & [1500-115200] & \\
\hline \multirow[t]{2}{*}{ Haemoglobin, gm/dl } & $10.4(2.6)$ & $9.8(3.0)$ & 0.302 \\
\hline & {$[3.6-14.2]$} & {$[3.8-13.9]$} & \\
\hline \multirow[t]{2}{*}{ White blood cells, cell/ $/ \mathrm{mm}^{3}$} & $5,122.7(1851)$ & $5,507.7(1,966)$ & 0.346 \\
\hline & {$[1,900.0-11,400]$} & {$[1,800.0-9,000.0]$} & \\
\hline \multirow[t]{2}{*}{ Blood glucose, mg/dl } & $110.7(44.3)$ & $106.8(28.3)$ & 0.670 \\
\hline & {$[30.0-198.0]$} & {$[30 .-170.0]$} & \\
\hline \multirow[t]{2}{*}{ Serum bilirubin, mg/dl } & $1.4(1.0)$ & $1.4(1.2)$ & 0.857 \\
\hline & {$[0.2-5.6]$} & {$[0.4-6.6]$} & \\
\hline \multirow[t]{2}{*}{ Serum creatinine, mg/dl } & $0.9(0.5)$ & $0.9(0.3)$ & 0.738 \\
\hline & {$[0.1-4.6]$} & {$[0.5-2.0]$} & \\
\hline
\end{tabular}

more vulnerable to anaemia and hypoglycaemia than adult non-pregnant patients.

Interestingly, it has been observed that $36.2 \%$ of adult patients in the same study area had anaemia regardless of their age, sex, education level or infection with malaria [12]. In Tanzania, the clinical manifestations of severe malaria in children younger than five years were cerebral malaria (47.3\%) and severe anaemia (14.6\%) [4]. Severe anaemia $(8.57 \%)$ and circulatory collapse (11.90\%) were the most common manifestations of severe malaria in neighbouring Ethiopia [13]. In Southeast Asia, which is characterized by unstable malaria transmission, the incidence of anaemia and convulsions decreased with age, whereas the incidence of hyperparasitaemia, jaundice, and renal insufficiency increased with age [14]. In India, acute renal failure and jaundice were more common in adults whereas children frequently developed severe anaemia, while cerebral malaria occurred equally in adults

Table 2 Comparison of clinical and biochemical characteristics of three main groups with severe malaria

\begin{tabular}{|c|c|c|c|c|}
\hline Variable & $\begin{array}{l}\text { Convulsion } \\
(N=18)\end{array}$ & $\begin{array}{l}\text { Cerebral malaria } \\
(\mathrm{N}=23)\end{array}$ & $\begin{array}{l}\text { Hypotension } \\
(\mathrm{N}=38)\end{array}$ & $P$-value \\
\hline Age, years & $39.5(1.6)$ & $43.0(1.7)$ & $36.4(1.5)$ & $<0.001$ \\
\hline Haemoglobin, gm/dl & $11.3(3.1)$ & $11.2(2.1)$ & $9.7(2.2)$ & 0.020 \\
\hline Blood glucose, mg/dl & $106.5(29.5)$ & $123.2(33.1)$ & $115.9(54.0)$ & 0.485 \\
\hline White blood cells, cell/mm3 & $5,650(1,804)$ & $5,991(2,137.8)$ & $5,229.0(2,078)$ & 0.361 \\
\hline Geometric mean of asexual stage parasitaemia per $\mu \mathrm{L}$ & $4,339.7(60,436)$ & $7,986.7(82,014)$ & $5,831.9(67,614)$ & 0.986 \\
\hline
\end{tabular}


and children [15]. One tenth (10.8\%) out of these 139 patients presented with hypoglycaemia. It was previously shown that $20 \%$ and $16 \%$ of children with severe malaria in Malawi and Kenya, respectively, had hypoglycaemia before treatment $[16,17]$. Hypoglycaemia is one of the defining features of severe malaria according to WHO guidelines, and indicates a poor prognosis [2]. Furthermore, it is a treatable cause of other features of severe malaria e g, coma and convulsions, especially in severe childhood illnesses [2]. Recent findings showed a significant difference between blood glucose levels between children who died and survivors [18].

The manifestations of severe malaria were not significantly different between $P$. falciparum and $P$. vivax malaria in this report. Previously, $P$. vivax was considered the cause of tertian benign malaria that rarely led to a severe form of the disease. However, increasing evidence has shown an increased risk of mortality and morbidity owing to $P$. vivax malaria [10,19-22]. Generally, most reports on severe $P$. vivax malaria are from Southeast Asia and India, and there have been few published data on severe $P$. vivax from Africa. It has been documented different manifestations of severe $P$. vivax malaria among children in a nearby hospital (New Halfa) [10]. The clinical presentation of severe malaria caused by $P$. vivax in India presented with cerebral malaria, severe anaemia, renal failure, hypoglycaemia, jaundice, acute respiratory distress syndrome, shock, and death [20]. However, to the best of the knowledge, there have been no reports from African countries regarding adult patients with malaria. Of note, there are no specific manifestations or treatment for severe $P$. vivax malaria, but according to the WHO guidelines, it should be considered as severe as $P$. falciparum malaria [11].

In the current study, three patients (2.0\%) died owing to severe $P$. falciparum malaria. In Tanzania, the fatality rate of severe malaria was $3.2 \%$ and the majority of deaths occurred in children younger than five years [4]. High mortality rates (33.3\%), mainly in young adults, were observed among patients with severe malaria at Dakar, Senegal [23]. Likewise, a high fatality rate (24.1\%) was observed among 1,050 patients with severe malaria in Southeast Asia, where mortality increased from $6.1 \%$ in children to $36.5 \%$ in patients aged $>50$ years [15]. Low death rates may be caused by underestimation, as some cases of severe malaria might have died at home without access to hospital treatment. Furthermore, the low rate of hypoglycaemia in this study could explain the low mortality rate itself where recent study showed a significant difference between blood glucose levels between children who died and survivors [18]. It is also possible that genetic factors might explain the mortality in this setting.

There are some limitations of this study; manifestations of the disease itself were overlaps and might not be strictly followed e.g. hypotension is only severe disease if not responsive to fluids, bleeding by itself is not severity as well, unless it is followed by circulatory collapse and hyperbilirubinaemia is considered a severity criterion if its followed by other organ dysfunctions. Furthermore PCR was not performed in any sample of the patients to confirm the parasite species as has been done in some other setting [24].

\section{Conclusions}

Severe malaria due to $P$. falciparum or $P$. vivax malaria is an entity that exists among adults in eastern Sudan, with similar manifestations between severe $P$. falciparum and $P$. vivax.

\section{Competing interests}

The authors declare that they have no competing interests.

\section{Authors' contributions}

TMA and IA designed the study and shared in the statistical analyses. MTA and ISA conducted the clinical work. HZH and MMM conducted the biochemical work. All the authors shared in the draft and approved the manuscript.

\section{Acknowledgements}

Authors would like to thank the patients and their relatives, all the staff of Kassala hospital and Abdulla Hafazalla for his technical support. I Adam was supported by the National Malaria Control programme.

\section{Author details}

${ }^{1}$ Faculty of Medicine, Kassala University, PO Box 496, Kassala, Sudan. ${ }^{2}$ Faculty of Medicine, University of Khartoum, PO Box 102, Khartoum, Sudan. ${ }^{3}$ Faculty of Medicine, Al-Neelain University, Khartoum, Sudan.

Received: 2 April 2013 Accepted: 30 April 2013

Published: 1 May 2013

\section{References}

1. WHO: World Malaria Report 2010. Geneva: World Health Organization; 2010

2. $\mathrm{WHO} / \mathrm{Communicable} \mathrm{diseases} \mathrm{cluster:} \mathrm{Severe} \mathrm{falciparum} \mathrm{malaria.} \mathrm{Trans} R$ Soc Trop Med Hyg 2000, 94:S1-S90.

3. Eholié SP, Ehui $E$, Adou-Bryn K, Kouamé KE, Tanon A, Kakou A, Bissagnené Kadio A: Severe malaria in native adults in Abidjan (Côte d'Ivoire) (in French). Bull Soc Pathol Exot 2004, 97:340-344.

4. Msangeni HA, Kamugisha ML, Sembuche SH, Malecela EK, Akida JA, Temba FF, Mmbando BP, Lemnge MM: Prospective study on severe malaria among in-patients at Bombo regional hospital, Tanga, north-eastern Tanzania. BMC Infect Dis 2011, 11:256

5. Nadjm B, Mtove G, Amos B, Walker NF, Diefendal H, Reyburn H, Whitty CJ: Severe febrile illness in adult hospital admissions in Tanzania: a prospective study in an area of high malaria transmission. Trans $R$ Soc Trop Med Hyg 2012, 106:688-695.

6. Ali AA, Elhassan EM, Magzoub MM, Elbashir Ml, Adam I: Hypoglycaemia and severe Plasmodium falciparum malaria among pregnant Sudanese women in an area characterized by unstable malaria transmission. Parasit Vectors 2011, 4:88

7. Eltahir HG, Omer AA, Mohamed AA, Adam I: Comparison of artesunate and quinine in the treatment of Sudanese children with severe Plasmodium falciparum malaria. Trans R Soc Trop Med Hyg 2010, 104:684-686.

8. Giha HA, Elghazali G, A-Elgadir TM, A-Elbasit IE, Eltahir EM, Baraka OZ, Khier MM, Adam I, Troye-Blomberg M, Theander TG, Elbashir MI: Clinical pattern of severe Plasmodium falciparum malaria in Sudan in an area characterized by seasonal and unstable malaria transmission. Trans $R$ Soc Trop Med Hyg 2005, 99:243-251.

9. Himeidan YE, Elbashir MI, El-Rayah e-A, Adam I: Epidemiology of malaria in New Halfa, an irrigated area in eastern Sudan. East Mediterr Health J 2005, 11:499-504 
10. Mahgoub H, Gasim GI, Musa IR, Adam I: Severe Plasmodium vivax malaria among Sudanese children at New Halfa Hospital, Eastern Sudan. Parasit Vectors 2012, 5:154.

11. WHO: Guidelines for the treatment of malaria. 2010. [http://uww.who.int/malaria/ publications/atoz/9789241547925], Languages: English. ISBN 9789241547925.

12. Abdallah TM, Adam I, Abdelhadi MA, Siddig MF, Ali AA: Anemia among adults in Kassala, Eastern Sudan. BMC Res Notes 2012, 5:202.

13. Tekeste Z, Workineh M, Petros B: Determining the severity of Plasmodium falciparum malaria in Ethiopia. J Infect Public Health 2013, 6:10-15.

14. Dondorp AM, Lee SJ, Faiz MA, Mishra S, Price R, Tjitra E, Than M, Htut Y, Mohanty S, Yunus EB, Rahman R, Nosten F, Anstey NM, Day NP, White NJ: The relationship between age and the manifestations of and mortality associated with severe malaria. Clin Infect Dis 2008, 47:151-157.

15. Mohanty S, Mishra SK, Pati SS, Pattnaik J, Das BS: Complications and mortality patterns due to Plasmodium falciparum malaria in hospitalized adults and children, Rourkela, Orissa, India. Trans R Soc Trop Med Hyg 2003, 97:69-70.

16. Taylor TE, Molyneux ME, Wirima JJ, Fletcher KA, Morris K: Blood glucose levels in Malawian children before and during the administration of intravenous quinine for severe falciparum malaria. N Engl J Med 1988, 319:1040-1047.

17. English M, Wale S, Binns G, Mwangi I, Saurewein H, Marsh K: Hypoglycaemia on and after admission in Kenyan children with severe malaria. Q J Med 1998, 91:191-197.

18. Willcox ML, Forster M, Dicko Ml, Graz B, Mayon-White R, Barennes H: Blood glucose and prognosis in children with presumed severe malaria: is there a threshold for 'hypoglycaemia'? Trop Med Int Health 2010, 15:232-240.

19. Kochar DK, Tanwar GS, Khatri PC, Kochar SK, Sengar GS, Gupta A, Kochar A Middha S, Acharya J, Saxena V, Pakalapati D, Garg S, Das A: Clinical features of children hospitalized with malaria-a study from Bikaner, northwest India. Am J Trop Med Hyg 2010, 83:981-989.

20. Kute VB, Trivedi HL, Vanikar AV, Shah PR, Gumber MR, Patel HV, Goswami JG, Kanodia KV: Plasmodium vivax malaria-associated acute kidney injury, India, 2010-2011. Emerg Infect Dis 2012, 18:842-845.

21. Shaikh S, Memon H, Shaikh A, Ahmed I, lohano B, Baird KJ: Severe disease in children hospitalized with a diagnosis of Plasmodium vivax in southeastern Pakistan. Malar J 2012, 11:144.

22. Sharma R, Gohain S, Chandra J, Kumar V, Chopra A, Chatterjee S, Aneja S, Kumar Dutta A: Plasmodium vivax malaria admissions and risk of mortality in a tertiary-care children's hospital in North India. Paediatr Int Child Health 2012, 32:152-157.

23. Wade KA, Sene BE, Niang EM, Diallo A, Diatta B: Epidemiology and prognostic value of organ failure during severe malaria in the Principal Military Teaching Hospital of Dakar, Senegal (in French). Med Sante Trop 2012, 22:422-424.

24. Manning L, Laman M, Law I, Bona C, Aipit S, Teine D, Warrell J, Rosanas-Urgell A, Lin E, Kiniboro B, Vince J, Hwaiwhanje I, Karunajeewa H, Michon P, Siba P, Mueller I, Davis TM: Features and prognosis of severe malaria caused by Plasmodium falciparum, Plasmodium vivax and mixed Plasmodium species in Papua New Guinean children. PLoS One 2011, 6:e29203.

doi:10.1186/1475-2875-12-148

Cite this article as: Abdallah et al: Severe Plasmodium falciparum and Plasmodium vivax malaria among adults at Kassala Hospital, eastern Sudan. Malaria Journal 2013 12:148.

\section{Submit your next manuscript to BioMed Central and take full advantage of:}

- Convenient online submission

- Thorough peer review

- No space constraints or color figure charges

- Immediate publication on acceptance

- Inclusion in PubMed, CAS, Scopus and Google Scholar

- Research which is freely available for redistribution 